ROBERT J. KWORTNIK JR., W. MICHAEL LYNN, and WILLIAM T. ROSS JR.*

\begin{abstract}
Marketing scholars have proposed that service employees play a primary role in delivering service quality. However, the question of how to motivate service employees to enhance service production has received little research attention. The authors address this gap by advocating a control mechanism first discussed in the economics literature-buyer monitoring. The authors focus on a pervasive form of buyer monitoring, voluntary tipping, and examine the effectiveness of this control mechanism as a means for improving service in two contexts: leisure cruises and restaurant dining. Despite a substantial interdisciplinary literature reporting a weak relationship between customers' perceptions of service and their tipping behavior, the results show that a policy of voluntary tipping has positive effects on the motivation and behavior of service workers and on customers' perceptions of the service those workers provide. These findings call attention to buyer monitoring as both a topic for academic research and a practical mechanism for motivating service employees. The findings also call into question trends away from tipping in service contexts, such as the cruise industry, and suggest that many service businesses for which tipping is not viable can benefit from alternative forms of buyer monitoring.
\end{abstract}

Keywords: buyer monitoring, tipping, service quality, employee control mechanisms, personalized service

\title{
Buyer Monitoring: A Means to Insure Personalized Service
}

The emergence of the service economy has stimulated a wealth of research intended to help firms improve service production. Of particular interest to marketing scholars has been the domain of service quality-specifically, its conceptualization, measurement, and management (e.g., Berry, Parasuraman, and Zeithaml 2003; Brady and Cronin 2001; Parasuraman, Zeithaml, and Berry 1985). A review of this literature reveals that the "people" dimension of services is of particular importance. Grönroos (1984) identifies this factor as "functional quality" (how the service is delivered), and Brady and Cronin (2001) use the label "interaction quality" to reflect customers' perceptions of their service interactions with employees. However, although scholars

*Robert J. Kwortnik Jr. is Associate Professor of Marketing (e-mail: rjk34@cornell.edu), and W. Michael Lynn is Professor of Marketing (e-mail: wml3@cornell.edu), Cornell University School of Hotel Administration. William T. Ross Jr. is Smeal Research Fellow in Marketing and Professor of Marketing, Smeal College of Business Administration, Pennsylvania State University (e-mail: wtr2@psu.edu). Order of authorship was determined alphabetically. Jeff Inman served as associate editor for this article. argue that this interpersonal dimension often has the strongest influence on customers' quality perceptions for many services (Bitner, Booms, and Mohr 1994; Heskett, Sasser, and Schlesinger 1997; Suprenant and Solomon 1987), empirical research in marketing that shows how to motivate service workers and improve interaction quality is relatively scant.

When marketing scholars examine employee motivation and performance, they typically focus on the control mechanisms used to motivate salespeople (Anderson 1985). Approaching this topic from the perspectives of agency theory (Bergen, Dutta, and Walker 1992), transaction cost analysis (Rindfleisch and Heide 1997), and organization theory (Eisenhardt 1985), researchers have primarily examined behavioral and outcome control, with clan control being a third mechanism discussed but rarely studied (Anderson and Oliver 1987). However, these control mechanisms are less effective in many service contexts, such as hairstyling, restaurant dining, and travel planning, all of which are characterized by complex, unstandardized, and personalized interactions with customers. An alternative control mechanism is needed to ensure satisfactory delivery of these types of services. 
Perhaps ironically, we advocate a service control mechanism that requires managers to give up control-that is, to abdicate responsibility for monitoring and rewarding service workers to the customers being served. We propose that customers can play an important role in service production as de facto managers through a mechanism first discussed in the economics literature-namely, buyer monitoring (Jacob and Page 1980). For example, consumers of services are often given the task of monitoring and rewarding workers who served them through the custom of voluntary tipping. Among the service workers commonly tipped are bartenders, concierges, doormen, hairstylists, parking valets, porters, taxi drivers, tour guides, and waiters/waitresses (Star 1988). Estimates place the amount tipped to waiters and waitresses in North America at $\$ 47$ billion per year (Azar 2007), so worldwide, tips given to all service providers are substantial. Consumers' decisions about how much to tip are supposed to reflect their evaluations of the service and, therefore, to provide service workers with an incentive to deliver good service (Lynn and McCall 2000). Thus, tipping is an important employee control mechanism used to improve service quality. Surprisingly, whether tipping-and buyer monitoring in general-actually improves service has yet to be addressed empirically, despite conventional wisdom in support of this idea.

We first examined this question in a preliminary study conducted in the leisure cruise context. Recently, several cruise lines have shifted from voluntary tipping onboard to automatic service charges. However, before 2000, most cruise lines had a voluntary tipping policy, under which they encouraged cruisers to give cash-filled envelopes on the last day of the cruise to the staff who had served them. At that time, a few lines built tips into the price of the cruise and then discouraged tipping and/or prohibited employees from accepting tips. Our study capitalized on these differences to compare the average of dining room and cabin service ratings (on ten-point scales) for cruise ships operating under pro-tipping policies with those operating under no-tipping policies. Data came from Ward's (1995) study, which provides expert ratings of service along with other ship information. Sampling one ship per cruise line from this data source, we found that service ratings were higher for the 54 cruise ships with voluntary tipping than for the 16 cruise ships with no tipping (estimated marginal means $=7.45$ versus $7.05 ; \mathrm{F}(1,61)=5.84, p<$ .02) after statistically controlling for factors potentially related to service ratings, such as the ratio of passengers to crew, the ratio of ship size to passengers, ship dress code, and price category. Thus, it appears that buyer monitoring affects service performance positively in the leisure cruise context.

This purported positive effect of buyer monitoring on service performance hinges on the mechanism's ability to motivate good service through performance-contingent rewards. However, in the case of the most common context for buyer monitoring, restaurant tipping, research shows an average correlation between customers' service ratings and the size of the tips provided of only .2 (Lynn and McCall 2000). As Cohen (1992, p. 156) argues, this is too small to be visible to the naked eye of the careful observer, leading some scholars to question the incentive value of tipping (Azar 2009; Lynn 2003; Schwartz 1997). Indeed, Azar (2009) notes that the generally high level of service observed in studies of tipping is surprising given that customers' perceptions of service are only weakly related to the tips they leave-an apparent inconsistency he labeled the "tipping-service puzzle."

These interrelated issues-service quality in complex, customizable service contexts; appropriate service control mechanisms in such contexts; and the tipping-service puzzle-call for theoretical and empirical treatment of a new means to improve the service experience. We address this call and make three contributions to the marketing literature. First, we introduce buyer monitoring as a service control mechanism and develop the idea proposed by economists that buyers can sometimes monitor and reward service workers more efficiently than firms. Second, we offer the first empirical tests of the service-enhancing effects of buyer monitoring, which we show not only motivates good service but also encourages customeroriented service behaviors better than other service control approaches. Third, we provide conceptual arguments and empirical findings that resolve the tipping-service puzzle. Specifically, we argue that the motivational effects of buyer monitoring depend more on the perceived contingency between the service employees believe they deliver and the rewards they receive than on the actual contingency. We show that despite a weak relationship between customers' evaluations of service and their tipping behavior, the vast majority of servers believe that they can earn much larger tips by delivering better service. We also illustrate a form of multimethod triangulation that yields convergent findings in support of our main hypothesis.

\section{BUYER MONITORING AS A SERVICE CONTROL MECHANISM}

The employee control mechanisms discussed in the marketing and management literature streams are not well suited for complex, highly customizable services. Behavioral control, or the direct supervisory monitoring and rewarding of employee behavior, requires specifying desired employee behaviors as inputs to production (Anderson and Oliver 1987; Banker et al. 1996). This is difficult for many services because of heterogeneity in customers' needs and wants and in service production and delivery. For example, one restaurant dining party might want to be left alone, while another dining party might want to be fawned over by the server. This customized nature makes many services low in task programmability, undermining the effectiveness of behavioral control (Banker et al. 1996).

In general, outcome control, or the objective measurement and rewarding of results, is more effective than behavioral control in service contexts with low task programmability (Banker et al. 1996; Eisenhardt 1985). For example, sales outcomes are easily measured and rewarded, so outcome control is good for motivating speedy service, suggestive selling, and other service behaviors that enhance sales. In contrast, the satisfaction of customers' more idiosyncratic desires is difficult to measure, so outcome control is less effective for motivating more personal and customized service efforts.

Clan control, or the socialization of employees to identify with and be loyal to the organization, is presumably effective in Eastern countries (e.g., Japan), where it resonates with communalist values, but is less popular and of 
questionable effectiveness in Western countries (e.g., the United States), where it clashes with individualist values (Saleh 1982). Moreover, the effort and time needed to socialize employees make clan control difficult when employee turnover is high (Ouchi 1979), as is the case with many services (Hinkin and Tracey 2000). These issues suggest that clan control is unlikely to offer Western service firms assurance of good service.

We propose buyer monitoring as an alternative service control mechanism that is appropriate in many service contexts, especially when task programmability, outcome measurability, and employee retention are low (e.g., hospitality services). The concept of buyer monitoring was first introduced in the economics literature (Jacob and Page 1980) as an extension of Alchian and Demsetz's (1972) theory of the firm. From this economic perspective, firms exist because they can monitor and price production inputs more efficiently than consumers. This comparative advantage enables firms to profit by contracting with input owners and selling production outputs at a price that is less than the cost to consumers of overseeing production themselves. However, employee inputs to customized services are difficult for firms to monitor and price. Customers can often evaluate and reward employees' service efforts more efficiently than firms, so this responsibility is left up to customers through buyer monitoring (Azar 2004; Jacob and Page 1980). For example, the institution of tipping is widely used to motivate employees to deliver fast, attentive, friendly, and personalized service. Speedy and attentive service can also be motivated by outcome control in the form of commissions and service charges, but if friendly and personalized service is valued, tipping is presumed to be more efficient and effective because it is difficult and costly for firms to monitor and reward these latter aspects of service. ${ }^{1}$ Other forms of buyer monitoring are uncommon, but their potential exists in such exchange contexts as travel or real estate services, in which agents are supposed to represent the buyer when identifying products that best meet his or her individual preferences. Many such exchange relationships are currently structured to favor the seller, which monitors and rewards the agent through sales commissions, so developing suitable forms of buyer monitoring for these relationships would better align agent incentives with customers' interests.

As with traditional forms of behavioral and outcome control, buyer monitoring relies on extrinsic incentives to motivate employee behavior. Studies show that performance-based reward systems increase worker and firm productivity (Banker et al. 1996, 2000). A key distinction between buyer monitoring and other forms of employee control mechanisms is that buyer monitoring leaves the decision about appropriate employee compensation to the customer, even if delivery of that compensation is routed through the firm. Other forms of customerinfluenced employee control mechanisms are possible (e.g., teaching evaluations tied to merit pay, customer satisfaction ratings tied to employee bonuses), but under these mecha-

\footnotetext{
${ }^{1} \mathrm{~A}$ modern myth often mentioned in the academic literature and popular press is that the word TIP is an acronym for "to insure promptness." However, fast service can be easily motivated with outcome controls, as we show in Study 3, so tipping is not necessary to insure promptness. What tipping does help do is to insure personalized service; thus, we suggest the acronym TIPS.
}

nisms, the firm decides on the size of employee rewards using input from customers. By taking the decision about reward size out of customers' hands, these other mechanisms reduce customer control and, with it, some of the incentive for workers to satisfy each individual customer.

Another key distinction between buyer monitoring and other forms of employee control is that buyer monitoring is typically enforced through social norms rather than legal contracts. The idiosyncratic and often fleeting nature of customer-employee interactions makes written and legally binding contracting inefficient and impractical. Under buyer monitoring, customers are expected to reward service workers on the basis of the quality of the service provided, but services are rendered before payment, so customers can evaluate service any way they want and pay as little or as much as they like; service workers have no legal recourse if they are dissatisfied with the compensation received for their efforts. Thus, the effectiveness of buyer monitoring, unlike that of traditional behavioral and outcome controls, rests on the power of social norms to ensure that buyers actually monitor employee performance and reward it fairly.

Some economists argue that social norms are an effective mechanism for governing behavior and improving economic efficiency, and they point to tipping as an example of such efficiency-enhancing norms (Azar 2005; Conlin, Lynn, and O'Donoghue 2003). However, there is reason to question the effectiveness of social norms to ensure that buyers actually monitor and reward service performance because research on tipping in restaurants, for which there is a clear and well-known tipping norm, suggests that buyers provide rewards that vary only weakly with service performance. This finding has led scholars in economics (Azar 2009), services marketing (Lynn and Withiam 2008), hospitality management (Lynn 2003), and tourism (Schwartz 1997) to conclude that tipping cannot be relied on to motivate the delivery of good service. We propose that these scholars have overdrawn their conclusions. Although the relationship between service ratings and tip sizes in restaurant settings is weaker than expected, the relationship is positive and statistically reliable (Lynn and McCall 2000). Furthermore, field experiments show that server behaviors associated with more personalized and friendly service causally affect the tips customers leave (Lynn 2006). Thus, there is clear evidence that buyers monitor service and reward servers accordingly. Moreover, servers' expectations and motivations may lead them to perceive the relationship between service and tip size as stronger than it actually is.

Both cultural wisdom and consumer self-reports identify service quality as the main determinant of tip size (Adelman 1985; Speer 1997), so servers are likely to have a priori social expectations that tips are a reward for service. Furthermore, the anthropologist Daniel Suarez (2009) argues that service workers are motivated to perceive a strong relationship between their service efforts and tip rewards because they do not want to view themselves as the undeserving recipients of charity. People tend to perceive expected relationships between variables even when those relationships are weak (Fiedler 2000) and tend to believe that they have more control over events than they actually do (Presson and Benassi 1996), so servers' expectations and need for control may lead them to believe that tips are strongly affected by service. Therefore, this form of 
buyer monitoring should increase service levels despite the modest correlation between evaluations of service and tip sizes observed in research. Indeed, the weak correlation observed between customers' service ratings and tip sizes may in part reflect the success of tipping in reducing variability in service levels by motivating good service and attracting and retaining good workers (Bodvarsson and Gibson 1999).

In summary, giving customers the task of monitoring and rewarding service delivery is believed to be an efficient way to provide service workers with incentives to deliver good service tailored to the idiosyncratic needs of each customer. There are theoretical reasons to believe that buyer monitoring motivates service workers to deliver friendly and personalized service; however, there are also empirical reasons to doubt these effects. Ultimately, whether buyer monitoring actually motivates good service is an empirical question - one that has yet to be addressed in research. These ideas lead to our core hypothesis:

$\mathrm{H}_{1}$ : Buyer monitoring motivates service employees to provide more friendly and personalized service, which enhances customers' evaluations of the service provided.

We test this hypothesis along with several corollary hypotheses in three subsequent studies with different data sources and research methods. Study 1 replicates the results of the preliminary study and uses cross-sectional, correlational data to show that service ratings are better at restaurants with a policy of voluntary tipping than at restaurants with automatic service charges. Study 2 uses an online survey of restaurant servers to show that most servers believe that tips are affected by service and that the stronger their perceptions of this service-tip contingency, the more likely they are to engage in service-enhancing behaviors. Study 3 uses a scenario-based experiment to show that restaurant servers' motivation and inclination to provide personalized service are greater under tipping than under service charge or service-inclusive pricing policies, while their motivation and inclination to provide fast, salesenhancing service are the same under voluntary tipping and service charge policies but lower under a service-inclusive pricing policy. We conclude by discussing the theoretical and practical implications of these findings along with directions for further research.

\section{STUDY 1}

In Study 1, we assess the effects of buyer monitoring on perceived service in the restaurant industry-specifically, restaurants in Miami Beach, Fla. Miami attracts a large number of international tourists who are unfamiliar with U.S. tipping norms, so approximately $40 \%$ of restaurants in Miami Beach replaced voluntary tipping with automatic service charges. This enabled us to test $\mathrm{H}_{1}$ by comparing service ratings from restaurants with voluntary tipping with those from restaurants with service charges.

\section{Method}

Data sources. Restaurants served as the unit of analysis. The data came from two sources: Zagat's (2005) guide to Miami Beach restaurants and telephone calls placed to the restaurants in the fall of 2006. We called all 154 restaurants with complete listings in the Zagat guide to ask about their tipping policy. However, we dropped 47 restaurants from the sample for various reasons (e.g., telephone numbers were disconnected, the Zagat guide indicated unreliable ratings due to low numbers of raters). Thus, our final sample consisted of 107 restaurants for which we had information about tipping policies and reliable service ratings.

Variables. The dependent variable was the restaurant's Zagat service rating on a 30-point scale, which reflects the following levels: 0-9 ("poor"-“fair"), 10-15 ("fair""good"), 16-19 ("good"-"very good"), 20-25 ("very good"-"excellent"), and 26-30 ("extraordinary""perfection"). The main independent variable was tipping policy (voluntary tipping or service charge). Restaurants that added a service charge only to large parties (five or more) were coded as having voluntary tipping. Additional variables from the Zagat guide used as controls included ratings of food and decor (on the same 30-point scale) and the average estimated cost of one dinner. Because we expected a relationship between service and price or decor (with higher prices in more fine-dining restaurants, in which better service is the norm) and between service and food (with efficiently and aesthetically presented food reflecting better service), we included these controls to isolate the effects of tipping policy on service by removing other effects from the analysis.

\section{Results}

A regression of the service measure on food, decor, and cost produced significant effects for food and restaurant expensiveness (Table 1). More important, adding a tipping policy to the model significantly improved the model's $\mathrm{R}$-square $\left(\Delta \mathrm{R}^{2}=.02 ; \mathrm{F}(1,102)=6.84, p=.01\right)$. Restaurants with voluntary tipping had higher average service ratings than restaurants with service charges (estimated marginal means $=19.46$ versus $18.54 ; \mathrm{t}(102)=2.62$, one-tailed $p<.01)$. This finding echoes the results from the preliminary study and indicates that the improvement in perceived service produced by buyer monitoring generalizes across at least some industries. However, the use of perceived service as a dependent measure means that we cannot be sure

Table 1

TIPPING AND HIGHER SERVICE RATINGS

\begin{tabular}{|c|c|c|c|c|}
\hline & $B$ & $\begin{array}{l}\text { Standard- } \\
\text { ized Beta }\end{array}$ & $t$-Statistic & $\begin{array}{c}\text { Two-Tailed } \\
\text { p-Value }\end{array}$ \\
\hline \multicolumn{5}{|l|}{ Model 1} \\
\hline (Constant) & 3.72 & & 2.60 & .011 \\
\hline Food rating & .55 & .54 & 8.11 & .000 \\
\hline Decor rating & .09 & .14 & 1.53 & .129 \\
\hline Restaurant expensiveness & .05 & .30 & 2.87 & .005 \\
\hline \multicolumn{5}{|c|}{$\mathrm{R}^{2}=.68 ; \mathrm{F}(3,103)=73.17, p<.001$} \\
\hline \multicolumn{5}{|l|}{ Model 2} \\
\hline (Constant) & 4.11 & & 2.94 & .004 \\
\hline Food rating & .49 & .48 & 6.97 & .000 \\
\hline Decor rating & .11 & .18 & 1.99 & .049 \\
\hline Restaurant expensiveness & .05 & .29 & 2.85 & .005 \\
\hline $\begin{array}{l}\text { Tipping is replaced with a } \\
\text { service charge } \\
\mathrm{R}^{2}=.70 ; \mathrm{F}(4,102)=59.70, p\end{array}$ & $\begin{array}{r}-.93 \\
<.001\end{array}$ & -.35 & 2.62 & .010 \\
\hline
\end{tabular}

Notes: Dependent measure is the Zagat rating of service quality. 
that tipping improved actual server motivation and/or service delivery. Consumers believe that tipping offers an incentive to deliver good service (Mills and Riehle 1987), so they may use a tipping policy as a cue when evaluating their service experiences. In other words, voluntary tipping may have a direct effect on perceptions and evaluations of service that is independent of its effects on employee motivation and behavior. Studies 2 and 3 provide more direct evidence that voluntary tipping improves service and not just consumers' perceptions of service.

\section{STUDY 2}

In Study 2, we examine the idea that tipping motivates employees to deliver better service, which rests on their perception that rewards are contingent on the service they deliver. To the extent that workers believe that they will receive larger tips for better service, they should be more willing to do the things necessary to satisfy customers. This leads to the following hypothesis:

$\mathrm{H}_{2}$ : Service employees working under a buyer-monitoring system who believe that customer rewards vary strongly with service engage in positive service behaviors more often than employees who believe that customer rewards vary only weakly with service.

\section{Method}

Data source. Restaurant servers completed an online survey about their experiences on and opinions of the job. We recruited participants by sending invitations to students, to members of commercial consumer lists (DataCorp) and panels (Zoomerang) who indicated that they were servers, and to people on Facebook and MySpace.com whose profiles indicated that they were servers. We also asked for recruitment help from industry managers, Web sites that attract servers (e.g., http://www.waiterrant.net), and survey respondents. We retained data from 1189 current servers across 48 states in the United States for analysis.

Variables. We obtained responses to the following measures: (1) perceived service-tip contingency: ratings of servers' beliefs about the effect of the quality of service delivered on tip size (five-point scale: $1=$ "very small effect," $3=$ "medium size effect," and $5=$ "very large effect"); (2) service behavior index: average rating of how often the server engaged in nine positive service behaviors (Lynn 2003), such as introducing oneself by name to customers and telling customers jokes or stories (four-point scale: $1=$ "never," 2 = "sometimes," 3 = "often," and $4=$ "all the time"); (3) comparative tip: rating of perceived tip size relative to tips earned by coworkers (seven-point scale: $1=$ "much smaller than most others" tips," $4=$ "about the same as most others' tips," and $7=$ "much larger than most others' tips"); and (4) restaurant bill size: average perperson bill size at the restaurant where the server works.

\section{Results}

Only $13 \%$ of survey respondents reported that service had a small or very small effect on tips, $37 \%$ reported that service had a medium effect, and 50\% reported that service had a large or very large effect. Thus, a substantial majority of servers perceived a meaningful contingency between the service they deliver and the tips they receive, which stands in stark contrast to the weak relationship reported in the literature between customers' evaluations of service and the tips they provide (Lynn and McCall 2000). Moreover, servers' perceptions of the strength of the service-tip contingency were significantly and positively correlated with the average frequency of positive service behaviors they perform $(\mathrm{r}=.17, \mathrm{n}=1171, p<.001)$. Separate analyses for each service behavior produced similar results (Table 2). These findings support $\mathrm{H}_{2}$, as well as our resolution of the tipping-service puzzle.

The positive correlation between the perceived servicetip contingency and the service behavior index supports the idea that the perceived contingency motivates good service. Yet it could also be due to a reverse causal effect because the service behaviors included in the index are known to increase tips (Lynn 2003). Therefore, servers who frequently perform these behaviors should earn larger tips than coworkers who perform the behaviors less often, and this difference in tip income could drive perceptions of the service-tip contingency. Furthermore, the relationship between the perceived service-tip contingency and service behaviors could be due to the confounding effects of restaurant expensiveness. Many acts in the service behavior index are too informal for high-end restaurants, so servers working at these restaurants may be less likely to engage in these behaviors. Servers at such restaurants might also perceive a weaker service-tip contingency either because there is less variability in service at these restaurants or because social pressures to tip at these restaurants undermine the actual service-tip contingency.

To address these alternative explanations, we regressed the service behavior index on comparative tips, restaurant bill size, and perceived service-tip contingency (Table 3 ). This analysis produced significant effects for comparative tips but not for restaurant expensiveness. More important, it produced a significant effect for the perceived service-tip contingency $(\mathrm{B}=.07, \mathrm{t}(1152)=4.40, p<.001)$. The relationship between perceived service-tip contingency and the service behavior index remained significant even after we controlled for these factors, thus ruling out the reverse causality and confounding explanations. Other explanations

Table 2

\section{POSITIVE SERVICE BEHAVIORS OF SERVERS WHO PERCEIVE A SERVICE-TIP CONTINGENCY}

\begin{tabular}{lcc}
\hline \hline Behavior & $n$ & $r$ \\
\hline Calling customers by name & 1170 & $.16^{* *}$ \\
Touching customers & 1166 & $.15^{* *}$ \\
Smiling at customers & 1166 & $.15^{* *}$ \\
Attempts at suggestive selling & 1161 & $.14^{* *}$ \\
Telling customers jokes or stories & 1164 & $.11^{* *}$ \\
Complimenting customers' food choices & 1157 & $.10^{* *}$ \\
Introducing oneself by name & 1170 & $.06^{*}$ \\
Repeating customers orders back to them & 1167 & .02 \\
Writing "Thank You" on the back of checks & 1166 & -.02 \\
Mean frequency of positive service behaviors & 1171 & $.17^{* *}$ \\
\hline
\end{tabular}

$* p<.05$ (two-tailed).

$* * p<.005$ (two-tailed).

Notes: Correlations are between ratings of frequency of each behavior and ratings of the effect of service quality on tip size. 
Table 3

EFFECT OF PERCEIVED SERVICE-TIP CONTINGENCY ON SERVICE BEHAVIOR INDEX (AFTER CONTROLLING FOR TIP INCOME AND RESTAURANT EXPENSIVENESS)

\begin{tabular}{lcccc}
\hline \hline Model & & $\begin{array}{c}\text { Standard- } \\
\text { ized Beta }\end{array}$ & t-Statistic & $\begin{array}{c}\text { Two-Tailed } \\
\text { p-Value }\end{array}$ \\
\hline (Constant) & 2.61 & & 29.75 & .000 \\
$\begin{array}{l}\text { Server's tip income (relative } \\
\quad \text { to coworkers) }\end{array}$ & .08 & .16 & 5.20 & .000 \\
$\begin{array}{l}\text { Restaurant bill size } \\
\begin{array}{l}\text { Perceived service-tip } \\
\quad \text { contingency }\end{array}\end{array}$ & .00 & -.04 & -1.29 & .186 \\
\hline
\end{tabular}

Notes: Dependent measure is index of rated frequency of nine positive service behaviors. $\mathrm{R}^{2}=.05, \mathrm{~N}=1156, \mathrm{~F}=20.81, p<.001$ (two-tailed).

are possible, but these are the most plausible, and they are not responsible for the observed relationship. Although causal interpretations of correlational data are always uncertain, the results of this study support the idea that the performance-contingent nature of tipping motivates servers to deliver better service.

The correlations in Study 2 provide evidence for an incentive effect of tipping but cannot be used to assess the size of the effect. If fewer servers believed that tips varied with service, the counterfactual would increase variance in the perceived service-tip contingency, thus increasing the size of its correlations with server behaviors, but the counterfactual would also diminish the incentive effect of tipping. To assess the size of the incentive effect, it is necessary to compare the motivation and behavior of servers under voluntary tipping with those of servers under other policies. We designed Study 3 to permit such an assessment. In addition, Study 3 allows for stronger causal inferences than those afforded by the previous studies. The study also enables us to test an important boundary condition of buyer-monitoring effects on service-namely, that buyer monitoring improves customer-oriented service more than sales-oriented service when compared with other forms of outcome control.

\section{STUDY 3}

In Study 3, we use a scenario-based, role-playing experiment to test the effects of buyer monitoring on selfreported employee motivation and behavior. Several hundred current or former waiters and waitresses read a scenario describing a restaurant work situation that differed with regard to compensation system: voluntary tipping by the customers they serve, a service charge based on the size of the bill instead of voluntary tipping, or higher wages with no tipping. After reading the scenario to which they had been randomly assigned, participants rated their likely motivation levels and behaviors under that scenario.

This experimental design allowed for causal inferences about the processes underlying buyer monitoring as an employee control mechanism and an assessment of the magnitude of effects on server motivation and behavior. In addition, Study 3 tested an important boundary condition for buyer monitoring. Recall the theoretical argument that buyer monitoring should improve server motivation and effort to personalize and customize service because low task programmability and outcome measurability make other ways of controlling these aspects of service (hereinafter, we refer to this as "customer-oriented service") ineffective or inefficient. However, sales-oriented aspects of service can be efficiently motivated by outcome controls in the form of sales commissions or service charges, so tipping or other forms of buyer monitoring should be less effective at improving worker motivation and effort to engage in sales-oriented behaviors when such outcome controls are in place. Indeed, such outcome controls may be more efficient than buyer monitoring in motivating sales-oriented service behavior, such as suggestive selling and fast service. In the absence of such outcome controls, however, buyer monitoring is better than no employee control mechanism and should enhance sales-oriented motivation and behavior. This reasoning leads to the following hypotheses:

$\mathrm{H}_{3}$ : Customer-oriented service motivation and behavior are greater under a buyer-monitoring policy than under a service charge or a wages-only policy.

$\mathrm{H}_{4}$ : Sales-oriented service motivation and behavior under a buying-monitoring policy are the same or lower than under a service charge policy but are greater than under a wagesonly policy.

\section{Method}

Participants. Current and former restaurant servers were recruited for this experiment by asking a blogger who is popular among waitstaff (the Waiter at www.waiterrant.net) to post a link to the online experiment and encourage his readers with restaurant work experience to participate. We offered participants an opportunity to win one of several $\$ 100$ Amazon.com gift certificates in exchange for their time and effort. A total of 469 current or former restaurant servers participated in the study. Of these participants, $66 \%$ were female, $35 \%$ were under the age of $25,37 \%$ were ages 25 to $34,18 \%$ were ages 35 to 44 , and the rest were age 45 or older. Some participants failed to answer every question, so the samples sizes vary slightly across the analyses.

Stimuli and manipulations. We randomly presented the participants with one of six scenarios that described a restaurant work situation (for additional information, see the Web Appendix at http://www.marketingpower.com/ jmroct09). The different versions of the scenario reflected manipulations of the compensation system (tipping versus service charges based on bill size versus wages) and managerial supervision (low versus high supervision). The managerial supervision manipulation had no significant main or interaction effects on the dependent measures, so we collapsed across this factor in the analyses. After reading the scenario, participants were instructed to think about what it would be like to be a server at this restaurant. Next, they completed the dependent measures, manipulation checks, and other measures, which we describe in greater detail subsequently.

Dependent measures. Participants indicated on a sevenpoint scale ( 1 = "not motivated," and 7 = "very motivated") how motivated they would be under the scenario described to engage in a variety of service behaviors. These items loaded on one of two factors, which we labeled "sales- 
oriented service motivation" and "customer-oriented service motivation" (see Table 4). We averaged the items that loaded highly on each of these factors to form indexes with Cronbach's alphas of .85 and .88 , respectively.

Next, participants indicated on a seven-point scale $(1=$ "not frequently," and 7 = "very frequently") how often they would perform 21 different service actions. All but one of these items loaded on one of two factors, which we labeled "customer-oriented service behaviors" and "sales-oriented service behaviors" (see Table 4). Customer-oriented service behaviors focused on providing friendlier and more customized service. Sales-oriented service behaviors focused on moving customers in and out more quickly (thus increasing the number of tables the server could serve) or increasing the size of the bill. We averaged the items loading highly on each of these factors to form indexes that had Cronbach's alphas of .91 and .88 , respectively. We dropped the one item that did not load on either factor.

Manipulation checks. After completing the dependent measures, participants indicated how much they thought their pay would be affected by tips and sales. We also collected additional manipulation checks, a measure of attitude toward service, and demographic data, but these added little value, and thus we do not report them here for the sake of brevity and clarity.

\section{Results}

Separate analyses of variance indicated that our manipulation of the tipping policy significantly affected the perceived dependence of pay on tips $(\mathrm{F}(2,463)=159.84, p<.001)$ and perceived dependence of pay on sales $(\mathrm{F}(2,463)=$ $181.61, p<.001)$. Post hoc comparisons using least significant differences tests indicated that participants perceived the tip policy manipulations as intended (Table 5). First, participants rated the dependence of pay on tips as significantly higher under the voluntary tipping condition than under the service charge condition and significantly higher under the latter condition than under the wages-only condition. Although we expected the perceived dependence of pay on tips to be comparable under the service charge and wages-only conditions, the significant difference between these conditions is understandable if some of the servers interpreted service charges as automatic tips. Second, participants rated the dependence of pay on sales as significantly higher under the service charge condition than under the voluntary tipping condition and significantly higher under the latter condition than under the wages-only condition. This is an expected pattern of results because sales has a more reliable effect on pay under service charges, a less reliable but meaningful effect on pay under tipping, and no effect on pay under wages-only compensation.

Separate analyses of variance indicated that the tipping policy manipulation significantly affected customeroriented service motivation $(\mathrm{F}(2,466)=33.29, p<.001)$ and behavior $(\mathrm{F}(2,466)=29.20, p<.001)$, as well as sales-oriented service motivation $(\mathrm{F}(2,466)=254.57, p<$ $.001)$ and behavior $(\mathrm{F}(2,466)=173.01, p<.001)$. Consistent with $\mathrm{H}_{3}$, customer-oriented service motivation and behavior were both significantly higher under the voluntary tipping condition than under the service charge and the wages-only condition (Table 5). Consistent with $\mathrm{H}_{4}$, salesoriented service motivation and sales-oriented service
Table 4

STUDY 3: FACTOR LOADINGS OF MOTIVATIONAL AND BEHAVIORAL MEASURES

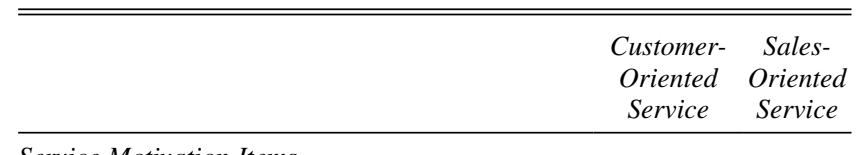

Service Motivation Items

How motivated would you be to provide friendly, enthusiastic service to your customers at this restaurant?

How motivated would you be to ask about and remember the individualized requests of your customers at this restaurant?

How motivated would you be to modify your service routine to accommodate your customers' individual needs and wants at this restaurant?

How motivated would you be to amuse and entertain your customers at this restaurant?

How motivated would you be to try to increase per-check dollar sales from your customers at this restaurant?

How motivated would you be to try to provide fast service to your customers to turn more tables at this restaurant?

Service Behavior Items

Visit the table to ask your customers if they are enjoying their meal.

Smile at your customers.

Ask your customers about their tastes and preferences to then recommend dishes.

Make unobtrusive passes by the table to observe your customers' needs.

Flirt or joke with your customers to entertain them.

Compliment your customers on their meal selections.

Add special garnishes to plates to make them more appealing to your customers.

Ask your customers questions about themselves to develop stronger relationships with them.

Thank your customers for their business either verbally or in writing on the check.

Ask the chef to prepare something off the menu for a customer who requests it.

Learn and use your customers' names.

Permit your customers to substitute items in an entrée, even if the kitchen does not like to do it.

Introduce yourself by name to your customers to be friendly.

Recommend specials and dishes with higher prices as your "favorites."

Attempt to up-sell your customers by suggesting additional (e.g., appetizers) or larger options (e.g., doubles).

Speed up the order and delivery process to turn tables more quickly.

Suggest branded selections (e.g., Bacardi) when your customers order unbranded choices.

Avoid suggesting dishes to your customers that take longer for the kitchen to prepare.

Ask for another server's help to clear your tables to make them available quicker.

Volunteer to serve large parties.

Notes: Pattern matrices are from separate factor analyses on motivational and behavioral items using generalized least squares as communalities and Promax rotation of two factors. 
Table 5

VOLUNTARY TIPPING PRODUCES HIGH LEVELS OF CUSTOMER-ORIENTED AND SALES-ORIENTED SERVICE

\begin{tabular}{lccc}
\hline \hline Measure & $\begin{array}{c}\text { Voluntary } \\
\text { Tipping }\end{array}$ & $\begin{array}{c}\text { Service } \\
\text { Charge }\end{array}$ & $\begin{array}{c}\text { Wages } \\
\text { Only }\end{array}$ \\
\hline Manipulation Checks & & & \\
Dependence of pay on tips & $5.88^{\mathrm{a}}$ & $5.15^{\mathrm{b}}$ & $2.29 \mathrm{c}$ \\
& $(1.71)$ & $(1.93)$ & $(1.97)$ \\
& $5.54^{\mathrm{a}}$ & $6.05^{\mathrm{b}}$ & $2.61^{\mathrm{c}}$ \\
Dependence of pay on sales & $(1.62)$ & $(1.52)$ & $(1.98)$
\end{tabular}

Dependent Measures

Customer-oriented service motivation $\quad 5.16^{\mathrm{a}} \quad 4.45^{\mathrm{b}} \quad 4.04^{\mathrm{c}}$

Customer-oriented service behavior $\quad(1.06) \quad(1.30) \quad(1.31)$

$\begin{array}{lll}4.85^{\mathrm{a}} & 4.42^{\mathrm{b}} \quad 3.91^{\mathrm{c}} \\ (.93) & (1.04) & (1.26)\end{array}$

(.93) (1.04) (1.26)

$\begin{array}{lrrr}\text { Sales-oriented service motivation } & 5.43^{\mathrm{a}} & 5.60^{\mathrm{a}} & 2.82^{\mathrm{b}} \\ & (1.03) & (1.34) & (1.28)\end{array}$

\begin{tabular}{llll} 
Sales-oriented service behavior & $4.82^{\mathrm{a}}$ & $5.06^{\mathrm{a}}$ & $2.92^{\mathrm{b}}$ \\
& $(1.06)$ & $(1.20)$ & $(1.09)$ \\
\hline
\end{tabular}

(1.06) (1.20) (1.09)

Notes: Means within each row with different superscripts are significantly different from one another at the .05 level (two-tailed). Those with the same superscript are not significantly different from one another.

behavior were comparable across the voluntary tipping and service charge conditions and were significantly higher under the voluntary tipping than under the wages-only condition.

To test $\mathrm{H}_{3}$ and $\mathrm{H}_{4}$ further, we standardized customer- and sales-oriented service motivation and entered them into a mixed between/within analysis of variance with tipping versus service charge as a between-subjects variable. We performed a similar analysis on customer- and salesoriented behavior. These analyses produced significant interactions between tipping policy and service dimension as implied by the hypotheses $(\mathrm{F}(1,309)=41.71$ and 26.17 for motivation and behavior, respectively, $p<.001$ ). With service charges as the comparison condition, voluntary tipping improved customer-oriented service motivation and behavior significantly more than it improved sales-oriented service motivation and behavior (Table 5).

The results of this study demonstrate that compensation policies causally affect the self-reported service motivation and behavior of restaurant servers. Customer-oriented service motivation and behavior increased by approximately half a standard deviation under voluntary tipping compared with service charges and increased by an even larger amount under voluntary tipping compared with wages only. In addition, the results support a boundary condition for buyer-monitoring effects on service. Theoretically, buyer monitoring should be most effective when both behavioral and outcome controls are weak. Service charges represent a strong outcome control for sales-oriented service but a weak outcome control for customer-oriented service. Thus, our finding that voluntary tipping improved customeroriented service motivation and behavior, but not salesoriented service motivation and behavior compared with a service charge policy, supports this theoretical boundary condition for buyer-monitoring effects.

\section{GENERAL DISCUSSION}

This investigation applies a multimethod approach across studies that use different data sources, designs, and contexts to triangulate on the effectiveness of buyer monitoring as a control mechanism to improve personalized service. Specifically, we find consistent evidence that buyer monitoring in the form of tipping positively affects workers' motivation to perform service-enhancing behaviors and customers' perceptions of service. We discuss the theoretical and practical implications of these findings along with directions for further research.

\section{The Tipping-Service Puzzle}

The results of our studies highlight an erroneous conclusion in the literature on tipping. Using the small correlation between customers' perceptions of service and the tips they leave as a basis, several scholars have concluded that tipping is unlikely to motivate good service (Azar 2009; Lynn 2003; Schwartz 1997). This conclusion underlies the puzzle identified by Azar (2009) that restaurant service levels are high despite research showing that tips are only weakly related to customers' service ratings. We help solve this tipping-service puzzle by arguing that the incentive value of tipping depends more on the perceived than the actual relationship between the service delivered and tips earned. Servers' expectations and illusions of control may lead them to perceive the service-reward relationship as stronger than it actually is; therefore, tipping provides an incentive for the delivery of good service. Our findings that the majority of servers believe that their tips are strongly affected by the service they deliver, that perceptions of this service-tipping contingency are related to servers' delivery of personalized service, and that voluntary tipping policies enhance employee motivation and performance support this reasoning.

Importantly, the observed effects of tipping policies on employee motivation and performance were large enough to be practically and theoretically meaningful. Voluntary tipping enhanced rated service by approximately one-half and one-third standard deviations in the preliminary study and Study 1, respectively, and enhanced customer-oriented service motivation and behavior by about a half a standard deviation (or more) in Study 3. Thus, managers in service industries should think twice before abandoning voluntary tipping policies.

The consequences of tipping extend beyond its effects on customer-oriented service motivation and behavior. On the positive side, tipping plays a direct role in the customer experience, and customers prefer tipping over service charges (Lynn and Withiam 2008). Tips are also a way to separate the price of service from the price of accompanying products (e.g., meals, lodging), so they are also a form of price partitioning that may reduce consumer perceptions of expensiveness (Morwitz, Greenleaf, and Johnson 1998). This partitioning of prices also lowers nominal prices for the accompanying products, which reduces costs when channels of distribution are paid a percentage of sales (e.g., travel agents). Finally, tipping allows different customers to pay different prices for the same service, so it is a form of price discrimination, which can increase profits (see Lynn and Withiam 2008; Schwartz 1997). On the negative side, tipping can motivate problematic behaviors, such as (1) discrimination against groups believed to be poor tippers, (2) collusion with customers against the firms' interest by giving goods and services free of charge, (3) refusal to attend 
to other servers' customers, and (4) shirking of collective tasks, such as backstage preparation and cleanup (Lynn and Withiam 2008). Thus, pros and cons to the use of tipping exist, and managers must weigh these considerations when deciding on compensation policies.

\section{Buyer Monitoring as an Employee Control Mechanism}

In addition to clarifying the tipping-service puzzle, our findings support the efficacy of buyer monitoring as an employee control mechanism that is particularly suitable for motivating friendly, personalized service. Marketing scholars have argued that the interaction between workers and customers is important for overall service quality but is difficult for service firms to control when different customers want different types of interactions with employees. If the firms' interests in delivering personalized service align with the customers' interests in receiving such service, firms can enlist the customers' help in monitoring and rewarding employees. Our finding that tipping improves customized services in restaurant contexts, in which the relationship between service ratings and tip size is typically weak, provides empirical support for the efficacy of tipping. As an employee control mechanism effective at enhancing an important and difficult-to-control aspect of service quality, buyer monitoring deserves more attention from marketing scholars. In particular, research is needed to identify and study other forms and consequences of buyer monitoring and the conditions that affect firms' use of buyer monitoring.

Other forms of buyer monitoring. Tipping, which involves direct customer monitoring of workers and rewarding their performance with voluntary gifts of money, is an efficient, pure form of buyer monitoring. There are other potential forms of buyer monitoring and rewarding of worker behavior, but rewards do not to come directly from the customer's pocket. For example, customers receiving multiple services from a team of workers could reward the team with money from a pool the customers fund and agree will be split according to the service each worker rendered. In cases involving smaller teams or solitary service workers, something similar could be achieved by having customers distribute funds between the employees and a third party (e.g., a charity) identified as a potential recipient if customers deem service performance to be inadequate. In both cases, the customers are rewarding employees with money they no longer consider theirs because they precommit to giving it away. The main benefit of these forms of buyer monitoring is the provision of a strong incentive for employees to satisfy the customer while reducing the customer's incentive to underreward employees, as can happen with tipping. This assurance would be especially valuable when the total reward a customer provides is large, either because many workers are involved (e.g., catered events, conventions) or because the value of the service is substantial (e.g., commissions paid to real-estate buyers' agents).

Another approach to buyer monitoring is for firms to build the cost of service into prices and let customers distribute to workers claims to some of the money as a reward for service. For example, Southwest Airlines has tried something similar by providing its frequent fliers with stickers to give to meritorious employees (Thomas 2008). Employees used the stickers as entries into a lottery (whose prizes ultimately came from airfares), so each sticker was a reward to the employees who received them. This form of buyer monitoring allows customers to determine how much each employee is rewarded relative to coworkers, thus preserving the incentive to satisfy customers. The firm can also mask the total rewards distributed to employees collectively, which permits the firm to charge more for employees' labor than it pays them and thus retain any funds not distributed in the form of customer-granted claims to employees.

Although these alternative forms of buyer monitoring are rare, they constitute an important area for further research. Certainly, there is a need for better ways to motivate customer-oriented behavior from service workers such as travel agents, real-estate brokers, and financial advisors who receive supplier-paid commissions on sales. Commissions give service workers larger rewards the higher the price customers pay, so they are a poor way to motivate workers to keep the best interest of the customer in mind. Other incentive schemes are needed to insure personalized service, and new forms of buyer monitoring may provide the needed incentives.

Other consequences of buyer monitoring. Although our research focuses on the effects of buyer monitoring on the delivery and customer perceptions of personalized service, buyer monitoring is a complex control mechanism that is likely to have other effects. For example, in addition to providing an incentive to deliver good service, buyer monitoring may selectively attract more competent and motivated service workers. Conversely, it also may cause deleterious effects, such as encouraging workers to discriminate against some customers, undermining workers' job satisfaction and retention due to conflicts of interest, and reducing workers' willingness to cooperate with coworkers and help with team processes that are necessary for service production.

First, effective buyer monitoring should lead to good performers earning more than less competent and motivated workers. Thus, firms that use buyer monitoring should attract and retain workers who believe in their own competence and/or are motivated by performancecontingent rewards. Although such selection effects have received little attention in marketing, research in other disciplines indicates that such effects are an important source of performance improvement caused by contingent compensation (Banker et al. 2000; Bouwens and Van Lent 2006; Harrison, Virick, and William 1996). Thus, testing the selection effects of buyer monitoring is a potential idea for further research.

Second, buyer monitoring provides an incentive to focus service on customers who leave large tips or servicecontingent tips while discriminating against others (Lynn and Withiam 2008). In a restaurant context, groups perceived as poor tippers and likely to receive inferior service include blacks, foreigners, teenagers, the elderly, and coupon users (Ayres, Vars, and Zakariya 2005; Harris 1995; Lynn 2004). This potential discrimination in service deliveryand the means for mitigating it-deserves more research attention.

Third, buyer monitoring places employees under the control of multiple masters. Workers must satisfy management and simultaneously satisfy multiple buyer monitors 
whose demands may conflict with one another or with those of management. Thus, buyer monitoring increases role conflict (Eddleston, Kidder, and Litsky 2002; Shamir 1983), which may produce deleterious effects on job satisfaction and retention (Hartline and Ferrell 1996; Singh, Goolsby, and Rhoads 1994). Effects of increased role conflict may be mitigated by the higher incomes earned by top performers under buyer monitoring (Lynn and Withiam 2008), but this issue needs to be empirically explored.

Finally, buyer monitoring rewards workers for service behaviors directed at and visible to their own customers but provides employees with a disincentive to help coworkers and to engage in important but less visible collective service tasks (Lynn and Withiam 2008). These disincentives and the ways to minimize them should be conceptually and empirically studied. For example, Barkan and colleagues (2004) find that pooling tips decreases competitive feelings among servers and, as long as workers can observe one another's efforts, increases service levels. Further research along these lines is needed.

Determinants of the use of buyer monitoring. Another direction for further research is to develop and test a theory on the conditions under which buyer monitoring is or should be used by firms. For example, building on the economic efficiency argument for buyer monitoring, Azar (2005) hypothesizes that tipping should be more common for occupations that customers can easily monitor (i.e., those with a large personal or social component and an easily assessed technical or professional component to the job). An analysis of tipped and nontipped service occupations does not support Azar's hypothesis, but additional research using different operationalizations of buyermonitoring ability and prevalence of tipping, as well as different occupations, is needed before definitive conclusions about that hypothesis can be drawn. In addition, other propositions about the conditions that promote the use of buyer monitoring need to be developed and tested.

\section{Conclusion}

As marketing scholarship and practice evolve toward a service-centric model of marketing exchange (Vargo and Lusch 2004), interdisciplinary, theory-driven research is needed to offer new perspectives and to expand the boundaries of extant principles and thought. Our adoption of the concept of buyer monitoring from economics and our evidence regarding its effectiveness are consistent with this research tradition. We offer insights from our multimethod studies and take the service-centric paradigm shift one step further by focusing on the role of consumers as de facto managers of service production, especially for services that are more complex and idiosyncratic. Marketers claim that "the customer is king." Now they need to acknowledge that the customer can also be the manager or the "buyer monitor."

\section{REFERENCES}

Adelman, Susan (1985), "How Your Customers Decide What to Tip," NRA News, (June-July), 43-44.

Alchian, Armen and Harold Demsetz (1972), "Production, Information, Costs, and Economic Organization," American Economic Review, 62 (December), 777-95.
Anderson, Erin (1985), "The Salesperson as Outside Agent or Employee: A Transaction Cost Analysis," Marketing Science, 4 (Summer), 234-54.

and Richard Oliver (1987), "Perspectives on BehaviorBased Versus Outcome-Based Sales Force Control Systems," Journal of Marketing, 51 (October), 76-88.

Ayres, Ian, Frederick Vars, and Nasser Zakariya (2005), "To Insure Prejudice: Racial Disparities in Taxicab Tipping," Yale Law Journal, 114 (7), 1613-74.

Azar, Ofer H. (2004), "Optimal Monitoring with External Incentives: The Case of Tipping," Southern Economic Journal, 71 (1), 170-81.

(2005), "Who Do We Tip and Why? An Empirical Investigation," Applied Economics, 37 (16), 1871-79.

(2007), "Do People Tip Strategically to Improve Future Service? Theory and Evidence," Canadian Journal of Economics, 40 (2), 515-27.

(2009), "Incentives and Service Quality in the Restaurant Industry: The Tipping-Service Puzzle," Applied Economics, 41 (15), 1917-27.

Banker, Rajiv D., Seok-Young Lee, Gordon Potter, and Dhinu Srinivasan (1996), "Contextual Analysis of Performance Impacts of Outcome-Based Incentive Compensation," Academy of Management Journal, 39 (4), 920-48.

—_ — - — Analysis of Continuing Improvements Following the Implementation of a Performance-Based Compensation Plan," Journal of Accounting and Economics, 30 (December), 315-50.

Barkan, Rachel, Ido Erev, Einat Zinger, and Mayan Tzach (2004), "Tip Policy, Visibility, and Quality of Service in Cafes," Tourism Economics, 10 (4), 449-62.

Bergen, Mark, Shantanu Dutta, and Orville C. Walker Jr. (1992), "Agency Relationships in Marketing: A Review of the Implications and Applications of Agency and Related Theories," Journal of Marketing, 56 (July), 1-24.

Berry, Leonard L., A. Parasuraman, and Valarie A. Zeithaml (2003), “Ten Lessons for Improving Service Quality," Marketing Science Institute Report No. 03-104, (May).

Bitner, Mary Jo, Bernard H. Booms, and Lois A. Mohr (1994), "Critical Service Encounters: The Employee's View," Journal of Marketing, 58 (October), 95-106.

Bodvarsson, Orn B. and William A. Gibson (1999), "An Economic Approach to Tips and Service Quality: Results of a Survey," Social Sciences Journal, 36 (1), 137-47.

Bouwens, Jan and Laurence van Lent (2006), "Performance Measure Properties and the Effect of Incentive Contracts," Journal of Management Accounting Research, 18, 55-75.

Brady, Michael K. and J. Joseph Cronin Jr. (2001), "Some New Thoughts on Conceptualizing Perceived Service Quality: A Hierarchical Approach," Journal of Marketing, 65 (July), 34-49.

Cohen, Jacob (1992), “A Power Primer,” Psychological Bulletin, 112 (1), 155-59.

Conlin, Michael, Michael Lynn, and Ted O’Donoghue (2003), "The Norm of Restaurant Tipping," Journal of Economic Behavior and Organization, 52 (3), 297-321.

Eddleston, Kimberly A., Deborah L. Kidder, and Barrie E. Litzky (2002), "Who's the Boss? Contending with Competing Expectations from Customers and Management," Academy of Management Executive, 16 (November), 85-95.

Eisenhardt, Kathleen (1985), "Control: Organizational and Economic Approaches," Management Science, 31 (February), 134-49.

Fiedler, K. (2000), "Illusory Correlations: A Simple Associative Algorithm Provides a Convergent Account of Seemingly Divergent Paradigms," Review of General Psychology, 4 (1), 25-58. 
Grönroos, Christian (1984), “A Service Quality Model and Its Marketing Implications," European Journal of Marketing, 18 (4), 36-44.

Harris, Mary B. (1995), "Waiters, Customers and Service: Some Tips About Tipping," Journal of Applied Social Psychology, 25 (8), 725-44.

Harrison, David A., Meghan M. Virick, and Sonja William (1996), "Working Without a Net: Time, Performance, and Turnover Under Maximally Contingent Rewards," Journal of Applied Psychology, 81 (4), 331-45.

Hartline, Michael D. and O.C. Ferrell (1996), "The Management of Customer-Contact Service Employees: An Empirical Investigation," Journal of Marketing, 60 (October), 52-70.

Heskett, James L., W. Earl Sasser Jr., and Leonard A. Schlesinger (1997), The Service Profit Chain. New York: The Free Press.

Hinkin, Timothy R. and J. Bruce Tracey (2000), "The Cost of Turnover: Putting a Price on the Learning Curve," Cornell H.R.A. Quarterly, 42 (June), 14-21.

Jacob, Nancy and Alfred Page (1980), "Production, Information Costs, and Economic Organization: The Buyer Monitoring Case," American Economic Review, 70 (June), 476-78.

Lynn, Michael (2003), "Tip Levels and Service: An Update, Extension, and Reconciliation," Cornell Hotel and Restaurant Administration Quarterly, 42 (December), 139-48.

(2004), "Ethnic Differences in Tipping: A Matter of Familiarity with Tipping Norms," Cornell Hotel and Restaurant Administration Quarterly, 45 (February), 12-22.

(2006), "Tipping in Restaurants and Around the Globe: An Interdisciplinary Review," in Handbook of Contemporary Behavioral Economics: Foundations and Developments, M. Altman, ed. Armonk, NY: M.E. Sharpe, 626-43.

__ and Michael McCall (2000), "Gratitude and Gratuity: A Meta-Analysis of Research on the Service-Tipping Relationship," Journal of Socio-Economics, 29 (2), 203-214.

and Glenn Withiam (2008), "Tipping and Its Alternatives: Business Considerations and Directions for Future Research," Journal of Services Marketing, 22 (4), 328-36.

Mills, Susan and Hudson Riehle (1987), "What Customers Think About Tips vs. Service Charges," Restaurants USA, (October), 20-23.

Morwitz, Vicki G., Eric A. Greenleaf, and Eric J. Johnson (1998), "Divide and Prosper: Consumers' Reactions to Partitioned Prices," Journal of Marketing Research, 35 (November), 453-63.
Ouchi, William G. (1979), "A Conceptual Framework for the Design of Organizational Control Mechanisms," Management Science, 25 (9), 833-48.

Parasuraman, A., Valarie A. Zeithaml, and Leonard Berry (1985), "A Conceptual Model of Service Quality and Its Implications for Future Research," Journal of Marketing, 49 (Fall), 41-50.

Presson, Paul K. and Victor A. Benassi (1996), "Illusion of Control: A Meta-Analytic Review," Journal of Social Behavior and Personality, 11 (3), 493-510.

Rindfleisch, Aric and Jan B. Heide (1997), "Transaction Cost Analysis: Past, Present, and Future Applications," Journal of Marketing, 61 (October), 30-54.

Saleh, S.D. (1982), "Management Systems in Japan and in North America," Industrial Management, 24 (September-October), $10-15$.

Schwartz, Zvi (1997), "The Economics of Tipping: Tips, Profits and the Market's Demand-Supply Equilibrium," Tourism Economics, 3 (3), 265-79.

Shamir, Boas (1983), "A Note on Tipping and Employee Perceptions and Attitudes," Journal of Occupational Psychology, 56 (3), 255-59.

Singh, Jagdip, Jerry R. Goolsby, and Gary K. Rhoads (1994), "Behavioral and Psychological Consequences of Boundary Spanning: Burnout for Customer Service Representatives," Journal of Marketing Research, 31 (November), 558-69.

Speer, Tibbett L. (1997), "The Give and Take of Tipping," American Demographics, 19 (2), 51-55.

Star, Nancy (1998), The International Guide to Tipping. New York: Berkeley.

Suarez, Daniel (2009), "Restaurant Tipping: Short-Circuiting Market Rationality and Non-Market Morality," Research in Economic Anthropology, 29, forthcoming.

Suprenant, Carol F. and Michael R. Solomon (1987), "Predictability and Personalization in the Service Encounter," Journal of Marketing, 51 (April), 86-96.

Thomas, Charles R. (2008), personal conversation with the Director of Financial Analysis Operations at Southwest Airlines (May 12).

Vargo, Stephen L. and Robert F. Lusch (2004), "Evolving to a New Dominant Logic for Marketing," Journal of Marketing, 68 (January), 1-17.

Ward, Douglas (1995), Berlitz Complete Guide to Cruising and Cruise Ships. New York: Berlitz.

Zagat Survey (2005), 2006 Miami Beach Restaurants. New York: Zagat Survey. 
Copyright of Journal of Marketing Research (JMR) is the property of American Marketing Association and its content may not be copied or emailed to multiple sites or posted to a listserv without the copyright holder's express written permission. However, users may print, download, or email articles for individual use. 